\title{
MEASUREMENTS AND MODELING OF TEMPERATURE- STRAIN RATE DEPENDENT UNIAXIAL AND PLANAR EXTENSIONAL VISCOSITIES FOR BRANCHED LDPE POLYMER MELT
}

\author{
Martin Zatloukal* \\ Polymer Centre, Faculty of Technology, Tomas Bata University in Zlin, \\ Vavreckova 275, 76272 Zlin, Czech Republic
}

Keywords: Orifice die, Planar extensional viscosity, Uniaxial extensional viscosity, Cogswell model, Entrance pressure drop, Polymer melts, Capillary rheometer, Constitutive equations.

*Corresponding author: mzatloukal@ft.utb.cz 


\begin{abstract}
In this work, novel rectangle and circular orifice (zero-length) dies have been utilized for temperature-strain rate dependent planar and uniaxial extensional viscosity measurements for the LDPE polymer melt by using standard twin bore capillary rheometer and Cogswell model and the capability of five different constitutive equations (novel generalized Newtonian model, original Yao model, extended Yao model, modified White-Metzner model, modified Leonov model) to describe the measured experimental data has been tested. It has been shown that chain branching causes the strain hardening occurrence in both unixial and planar extensional viscosities and its maximum is shifted to the higher strain rates if the temperature is increased. The level of uniaxial extensional strain hardening for the branched LDPE sample has been found to be higher in comparison with the planar extensional viscosity within wide range of temperatures.
\end{abstract}




\section{INTRODUCTION}

The extensional viscosity represents key rheological parameter allowing understanding the molecular structure of the polymers as well as polymer processing at which the polymer melts are stretched [1-27]. Due to the fact that generation and control of the extensional flow is difficult, experimental determination of the extensional viscosity is a problem [28-32]. Probably the most challenging rheological task is experimental determination of planar extensional viscosity as one can see from very small numbers of experimental data available in the open literature $[1-2,12-16$, 33]. With the aim to understand this important rheological parameter in more detail, in this work, novel rectangle and circular orifice dies [34-35] have been utilized for planar and uniaxial extensional viscosity measurements for branched LDPE by using standard twin bore capillary rheometer and Cogswell model $[6,12]$ and the capability of five different constitutive equations [36-42] to describe the measured experimental data has been tested.

\section{EXPERIMENTAL}

In this work, extrusion coating, branched LDPE CA820 from Borealis Polyolefine was used. Linear viscoelastic properties (storage modulus, loss modulus, and complex viscosity) were measured on Advanced Rheometric Expansion System ARES 2000 (Rheometrics Scientific, USA) in parallel plates geometry mode (plates diameter of $25 \mathrm{~mm}$ ) within $0.1 \mathrm{~s}^{-1}$ up to $100 \mathrm{~s}^{-1}$ frequency range at $1 \%$ shear strain to guarantee linear viscoelasticity regime only. In order to get storage and loss moduli for a large range of frequencies, the measurements were performed in a wide range of temperatures $\left(130-250^{\circ} \mathrm{C}\right)$. Possible degradation at high temperatures was suppressed 
by inert nitrogen atmosphere. The well-known time-temperature-superposition principle was used to generate master curves for particular reference temperature. Twin-bore capillary rheometer Rosand RH7-2 (Rosand Precision, United Kingdom) was used for experimental determination of uniaxial and planar extensional viscosities by using long as well as orifice dies having the abrupt contraction (i.e. $180^{\circ}$ entrance angle) and circular/rectangular shape (see Figures 1-2). The main advantage of both utilized orifice dies is the open downstream region design which eliminates any possibility for artificial pressure increase due to polymer melt touching the downstream wall [34-35]. Temperature measurement and control was performed at three separate zones in the barrel by using platinum resistance thermometers (PRTs) via microprocessor based board contained within the electronics rack communicating with the computer over a serial interface. Software running on the temperature board implements a three term (PID) control algorithm allowing independent variation of power for the three cuff barrel heaters with different heights and power ratings (1000W, 600W and 1000W).

The uniaxial and planar extensional viscosities have been determined through entrance pressure drop measurements by using the Cogswell model $[6,12]$ (see Table 1). In this table, $P_{0, \mathrm{U}}$ and $P_{0, \mathrm{P}}$ represents the entrance pressure drop measured on circular and rectangular orifice die, respectively, $Q$ is the volume flow rate, $R$ is the capillary die radius, $w$ and $h$ is the width and the gap size of the rectangle die, respectively, $P_{\mathrm{L}, \mathrm{U}}$ and $P_{\mathrm{L}, \mathrm{P}}$ represents the pressure drop through a long die having circular and rectangular shape, respectively, $L$ is the length of the long die. It should 
be mentioned that the long die has $L /(2 R)=16$ (or $L / h=16$ ) whereas the orifice die has $L /(2 R)=0.1208$ (or $L / h=0.1208)$ as suggested in [10].

The maximum attainable extensional strain during abrupt contraction flow in the capillary rheometer can be calculated as

$$
\varepsilon_{\text {max }}=\ln \left(\frac{A_{b}}{A_{d}}\right)
$$

where $A_{b}$ and $A_{d}$ is the cross-sectional area of the barrel and the die, respectively [43]. The barrel diameter of the rheometer is $15 \mathrm{~mm}$, diameter of the circular die is $2 \mathrm{~mm}$ and gap size of the rectangular die is $0.5 \mathrm{~mm}$. According to Eq. $1 \varepsilon_{\max }$ is 4 and 3.6 for circular and rectangle orifice dies, respectively, and thus the average strain achievable in both die can be considered to be comparable. Importance of comparing the extensional viscosity at the same strain level is discussed in [43-45]. Note that high shear rate rheology was evaluated via $1 \mathrm{~mm}$ diameter capillary dies.

\section{THEORETICAL}

\section{Generalized Newtonian Fluid Model}

In this work, recently proposed generalized Newtonian fluid model has been utilized [36-37]:

$$
\tau=2 \eta\left(I_{|\mathrm{D}|}, I I_{\mathrm{D}}, I I I_{\mathrm{D}}\right) D
$$

where $\tau$ means the extra stress tensor, $D$ represents the deformation rate tensor and $\eta$ stands for the viscosity, which is not constant (as in the case of standard Newtonian law), but it is allowed to vary with the first invariant of the absolute value of 
deformation rate tensor $I_{|\mathrm{D}|}=\operatorname{tr}(|D|)$, (where $|D|$ is defined as $\sqrt{D \cdot D}$ ) as well as on the second $I I_{\mathrm{D}}=2 \operatorname{tr}\left(D^{2}\right)$, and third, $I I I_{\mathrm{D}}=\operatorname{det}(D)$, invariants of $D$ according to Eq. 3

$$
\eta\left(I_{|\mathrm{D}|}, I I_{\mathrm{D}}, I I I_{\mathrm{D}}\right)=A^{1-f\left(I_{|\mathrm{D}|}, I I_{\mathrm{D}}, I I I_{\mathrm{D}}\right)} \eta\left(I I_{\mathrm{D}}\right)^{f\left(I_{|\mathrm{D}|}, I I_{\mathrm{D}}, I I I_{\mathrm{D}}\right)}
$$

where $\eta\left(I I_{D}\right)$ is given by the well known Carreau-Yasuda model (with infinite viscosity $\eta_{\infty}$ equal 0$)$, Eq. 4 and $f\left(I_{|\mathrm{D}|}, I I_{\mathrm{D}}, I I I_{\mathrm{D}}\right)$ is given by Eq. 5

$$
\begin{gathered}
\eta\left(I I_{\mathrm{D}}\right)=\frac{\eta_{0} a_{\mathrm{T}}}{\left[1+\left(\lambda a_{\mathrm{T}} \sqrt{I I_{\mathrm{D}}}\right)^{a}\right]^{\left(\frac{1-n}{a}\right)}} \\
f\left(I_{|\mathrm{D}|}, I I_{\mathrm{D}}, I I I_{\mathrm{D}}\right)=\left\{\tanh \left[\alpha a_{\mathrm{T}}\left(1+\frac{1}{4(\sqrt{3})^{3}}\right)^{-\psi /}\left(\left|1+\frac{I I I_{\mathrm{D}}}{I I_{\mathrm{D}}^{3 / 2}}\right|\right)^{\psi /} \frac{\sqrt[3]{4\left|I I I_{\mathrm{D}}\right|}+I_{|\mathrm{D}|}}{3}+\beta\right] \frac{1}{\tanh (\beta)}\right\}^{\zeta}
\end{gathered}
$$

here $A, \eta_{0}, \lambda, a, n, \alpha, \psi, \beta, \zeta$ are 9 adjustable parameters and $a_{\mathrm{T}}$ is temperature shift factor defined by the Arrhenius equation:

$$
a_{\mathrm{T}}=\exp \left[\frac{E_{\mathrm{a}}}{R}\left(\frac{1}{273.15+T}-\frac{1}{273.15+T_{\mathrm{r}}}\right)\right]
$$

where $E_{\mathrm{a}}$ is the activation energy, $R$ is the universal gas constant, $T_{\mathrm{r}}$ is the reference temperature and $T$ is local temperature.

The model utilizes 4 parameters $\left(\eta_{0}, \lambda, a, n\right)$ identifiable from shear viscosity, 4 parameters $(A, \alpha, \beta, \zeta)$ identifiable from uniaxial extensional viscosity and 1 parameter $(\psi)$, which can be determined from planar extensional viscosity. The key feature of this model is utilization of the new tensor called absolute value of deformation rate tensor, $|D|$, which characterizes deformation rate intensity in a particular direction (similarly to D) but without the information about its orientation 
(positive or negative). Its first invariant $I_{|\mathrm{D}|}$ becomes nonzero in extensional flows and thus the model has capability to predict uniaxial as well as planar extensional viscosities [36].

\section{Original Yao Model}

Original Yao model is a non-Newtonian fluid model with an objective vorticity tensor utilizing two different time scales for strain relaxation and rotation recovery [38]. Mathematically it takes the following form:

$$
\tau=G B^{*}+2 \eta_{S} D_{S}
$$

where $G$ is a modulus related to the chain structure, $B^{*}$ is an elastic strain tensor describing the conformation of the molecular coil

$$
B^{*}=\left[\exp \left(n_{0} \lambda a_{T} \overline{L^{*}}\right) \cdot \exp \left(n_{0} \lambda a_{T} \overline{L^{*}}\right)\right]^{\frac{1}{n_{0}}}
$$

$\eta_{S}$ is the slip viscosity defined as

$$
\eta_{S}=\frac{\mu_{S} a_{T}}{\left[1+\left(K_{1} a_{T} \sqrt{I I_{D_{S}}}\right)^{2}\right]^{(1-k) / 2}}
$$

where $I I_{D_{S}}$ is second invariant of deformation rate tensor for chain slip, $D_{S}$, defined as follows

$$
D_{S}=\frac{1}{2}\left[\left(L-\overline{L^{*}}\right)_{\perp}+\left(L-\overline{L^{*}}\right)_{\perp}^{T}\right]
$$

Here, $L$ is the velocity gradient, $\overline{L^{*}}$ is the adjusted objective velocity gradient introduced by Yao in [38] to enforce that the calculated stretch of the polymer coil does not exceed the ceiling stretch $S_{0}$. The symbol $\perp$ represents projection onto the 
principal directions of $B^{*}$. Even if the model utilizes 7 adjustable parameters $\left(\eta_{0}, \lambda, S_{0}\right.$, $\mu_{S} / \eta_{0}, n_{0}, K_{l}, k$ where $\left.\mathrm{G}=\eta_{0} / \lambda\right)$, its number is reduced to 6 for description of extensional flows because the parameter $n_{0}$ disappears in such a cases. Thus, all 6 original Yao model parameters $\left(\eta_{0}, \lambda, S_{0}, \mu_{s} / \eta_{0}, K_{l}, k\right)$ were identified on the uniaxial extensional viscosity only.

\section{Extended Yao Model}

Extended Yao model is a recently proposed non-Newtonian fluid model with finite stretch and rotational recovery utilizing specific finite chain dynamics to treat the combined effects of finite stretch and disentanglement [39], which reduce total number of model parameters from seven to five in comparison with the original Yao model. The extended Yao model is given by the following equations

$$
\begin{aligned}
\tau & =\frac{\eta_{0}}{\lambda\left[1-\frac{S}{S_{0}}\right]^{\beta_{0}}} B, \\
B & =\left\{\exp \left[n_{0} \lambda a_{T}\left(1-\frac{S}{S_{0}}\right) L\right] \cdot \exp \left[n_{0} \lambda a_{T}\left(1-\frac{S}{S_{0}}\right) L^{T}\right]\right\}^{\frac{1}{n_{0}}},
\end{aligned}
$$

where $B$ is the generalized Finger tensor representing the elastic strain accumulated in

the polymer coil and $S$ is an equivalent stretch, defined as $S=\sqrt{\frac{1}{6} \ln B: \ln B}$. The model utilizes 5 adjustable parameters $\left(\eta_{0}, \lambda, S_{0}, n_{0}, \beta_{0}\right)$, but its number is reduced to 4 for description of extensional flows due to disappearance of the parameter $n_{0}$ (i.e. similarly as in the case of original Yao model). Hence, all 4 extended Yao model parameters $\left(\eta_{0}, \lambda, S_{0}, \beta_{0}\right)$ were identified on the uniaxial extensional viscosity only. It 
is important to mention that according to Yao [39], the $\beta_{0}$ is the strain hardening parameter $\left(0 \leq \beta_{0} \leq 1\right)$ and $S_{0}$ is the celling stretch for disentanglement (typically in the range of 1 to 3 ).

\section{Modified White-Metzner Model}

Modified White-Metzner model constitutive equation is a simple Maxwell model for which the viscosity and relaxation time are allowed to vary with the second invariant of the strain rate deformation tensor [40]. It takes the following form:

$$
\tau+\lambda\left(I I_{\mathrm{D}}\right)^{\nabla}=2 \eta\left(I I_{\mathrm{D}}\right) D
$$

where $\stackrel{\nabla}{\tau}$ is the upper convected time derivative of stress tensor, $D$ is the deformation rate tensor, $I I_{\mathrm{D}}$ is the second invariant of the rate of deformation tensor, $\lambda\left(I I_{\mathrm{D}}\right)$ stands for the deformation rate-dependent relaxation time and $\eta\left(I I_{\mathrm{D}}\right)$ is the deformation ratedependent viscosity. Although this modification improves the behaviour in steady shear flows, in extensional flows the model predicts unrealistic infinite extensional viscosity. This problem was overcome by Barnes and Roberts [40], who showed that, for specific functions of $\lambda\left(I I_{\mathrm{D}}\right)$ and $\eta\left(I I_{\mathrm{D}}\right)$ with $\left(\lambda_{0} / K_{2}\right)<(\sqrt{3} / 2)$ (see Eqs. (4) and (13)), the model does not predict infinite extensional viscosity and can be used for a very good description of extensional viscosity of a wide range of real polymer melts:

$$
\lambda\left(I I_{\mathrm{D}}\right)=\frac{\lambda_{0} a_{\mathrm{T}}}{1+K_{2} a_{\mathrm{T}} I I_{\mathrm{D}}}
$$

where $\lambda_{0}$ and $K_{2}$ are constants. Eqs. $(4,12-13)$ together with the physical constraint for $\lambda_{0}$ and $K_{2}$ mentioned above represent the modified White-Metzner model. The model 
utilizes 4 parameters $\left(\eta_{0}, \lambda, a, n\right)$ identifiable from shear viscosity and 2 parameters $\left(\lambda_{0}, K_{2}\right)$ identifiable from uniaxial extensional viscosity.

\section{Modified Leonov Model}

This constitutive equation is based on heuristic thermodynamic arguments resulting from the theory of rubber elasticity [41, 46-47]. Mathematically it is relating the stress and elastic strain stored in the material as:

$$
\tau=2\left(c \frac{\partial W}{\partial I_{1}}-c^{-1} \frac{\partial W}{\partial I_{2}}\right)
$$

where $\tau$ is the stress, and $W$, the elastic potential, depends on the invariants $I_{1}$ and $I_{2}$ of the recoverable Finger tensor $c$,

$$
W=\frac{3 G}{2\left(n_{1}+1\right)}\left\{(1-\phi)\left[\left(\frac{I_{1}}{3}\right)^{n_{1}+1}-1\right]+\phi\left[\left(\frac{I_{2}}{3}\right)^{n_{1}+1}-1\right]\right\}
$$

where $G$ denotes linear Hookean elastic modulus, $\phi$ and $n_{1}$ are numerical parameters. Leonov assumed that dissipative process act to produce irreversible rate of strain $e_{\mathrm{p}}$

$$
e_{p}=b\left[c-\left(\frac{I_{1}}{3}\right) \delta\right]-b\left[c^{-1}-\left(\frac{I_{2}}{3}\right) \delta\right]
$$

which spontaneously reduces the rate of elastic strain accumulation. Here, $\delta$ is the unit tensor and $b$ stands for dissipation function defined by Eq. (18).This elastic strain $c$ is related to the deformation rate tensor $D$ as follows

$$
{ }^{0}-c \cdot D-D \cdot c+2 c \cdot e_{p}=0
$$


where $c$ is the Jaumann (corotational) time derivative of the recoverable Finger strain tensor. In this work, the neo-Hookean potential (i.e. $\phi=n_{1}=0$ in Eq. 15) and the dissipation function $b$ proposed in [42] (see Eq. 18), have been employed.

$$
b\left(I_{1}\right)=\frac{1}{4 \lambda a_{T}}\left\{\exp \left(-\xi \sqrt{I_{1}-3}\right)+\frac{\sinh \left[v\left(I_{1}-3\right)\right]}{v\left(I_{1}-3\right)+1}\right\}
$$

Here, $\xi$ and $v$ are adjustable parameters which are allowed to vary with relaxation time, $\lambda$. Thus, the model utilizes relaxation spectrum (in terms of finite number of $\lambda_{i}$ and $G_{i}$ pairs for given modes) identifiable from loss and storage moduli and 2 parameters $(\xi, v)$ identifiable from uniaxial extensional viscosity.

\section{RESULTS AND DISCUSSION}

The generalized Maxwell model was employed to fit the measured frequency dependent loss and storage moduli for the tested LDPE material to generate discrete relaxation spectrum. Figure 3 shows that this model properly fits the measured data, which supports the reliability of the estimated relaxation spectrum. The Newtonian viscosity at $170^{\circ} \mathrm{C}$ (calculated from the relaxation spectrum) and the flow activation energy (determined via Arrhenius plot depicted in Figure 4) was found to be 4376.6 Pa.s and $52.251 \mathrm{~kJ} / \mathrm{mol}$, respectively.

The measured temperature-strain rate dependent uniaxial and planar extensional viscosities, together with the shear viscosity and model fits/predictions (model parameters are summarized in Tables 2-6), for the tested branched LDPE sample are provided in Figures 5-10. 
First, the level of the strain hardening in uniaxial extensional viscosity is higher than in the planar extensional viscosity for the tested LDPE sample at all three temperatures (see Figures 5-6) which is in good agreement with the recent experimental work performed by D. Auhl et. al [33] on the cross-slot extensional rheometer. Experimental observation that the strain hardening is lower in planar extension than in uniaxial extension can be explained via differences in extensional flow kinematics and alignment strength (defined by Larson [48] as the strain invariants difference, $\left.\mathrm{I}_{1}-\mathrm{I}_{2}\right)$. In the uniaxial extension, material element is stretched in one direction and shrinks in another two directions, which leads to strong alignments of macromolecular chains along a single axis $\left(\mathrm{I}_{1}-\mathrm{I}_{2}>0\right)$. However, in the planar extension, the chain alignment is neutral $\left(\mathrm{I}_{1}-\mathrm{I}_{2}=0\right)$ because the material is stretched in one direction, shrinks in another direction but remains constant in the third direction [48]. This means that during uniaxial extension of polymer melts, alignment of macromolecular chains (i.e. the stress level) is much higher than in the case of planar extension. Thus, the observed higher extensional strain hardening of LDPE melt in uniaxial extension having $3 \mathrm{D}$ character can be attributed to more aligned and 'constrained' chains in comparison with planar extension having only 2D nature. Moreover, the investigated LDPE melt is highly branched, i.e. when the stretched chains become sufficiently close to each other, new entanglements start to occur due the presence of chain branches, which increases the resistance against the extensional flow. Thus, entanglement network can be much more strengthened via presence of chain branches in the uniaxial extension due to 3D character of geometric condensation, in which chains moves close to each other more effectively, than in the 
case of 2D planar extension. This may explain the observed extensional flow behaviour for the investigated LDPE melt.

Second, the maximum in both viscosities is shifted to the higher strain rates for increased temperature. It has been revealed recently [49-54] that the ratio of planar to uniaxial extensional viscosity, $\eta_{\mathrm{E}, \mathrm{P}} / \eta_{\mathrm{E}, \mathrm{U}}$, (i.e. the difference between the strainhardening nature in planar and uniaxial elongation) controls the level of the unwanted neck-in phenomena (film width reduction occurring during the film casting process between the flat die and the chill/nip rolls) due to the fact that the middle of the film undergoes planar elongation whereas the material at the edge undergoes uniaxial elongation. Based on the film casting process modeling, the following relationship between neck-in, $N I$, and planar to uniaxial extensional viscosity ratio has recently been found [53]:

$$
N I=\frac{1}{2}\left(W_{\mathrm{D}}-W_{\mathrm{F}}\right) \cong L\left\langle\frac{\eta_{\mathrm{E}, \mathrm{P}}}{\eta_{\mathrm{E}, \mathrm{U}}}\right\rangle_{L}^{1 / 2}
$$

where $W_{\mathrm{D}}$ represents the die exit width, $W_{\mathrm{F}}$ the final film width, respectively, $L$ is distance between the flat die and the chill/nip rolls and $\left\langle\eta_{\mathrm{E}, \mathrm{P}} / \eta_{\mathrm{E}, \mathrm{U}}\right\rangle$ is averaged planar to uniaxial extensional viscosity ratio. This suggests that the experimental evaluation of planar and uniaxial extensional viscosities can be considered as useful tool for optimization of the molecular structure of polymers utilized in the film casting technology to minimize neck-in phenomenon.

Third, the generalized Newtonian and both Yao models have higher capability to describe temperature-strain rate dependent uniaxial and planar extensional viscosities for both tested samples in comparison with modified White-Metzner models as visible 
in Figures 8-10. This can be explained by the presence of additional parameter $\psi$ in the generalized Newtonian model allowing to fit the deformation rate dependent planar extensional viscosity, which is not the case of the modified White-Metzner model. Even if the original Yao model shows a small tendency to over predict strain hardening in the measured planar extensional viscosity (see Figure 9), its overall capability to describe extensional rheology by using six physic-based material constants is very good due to implementation of finite stretch, disentanglement and slippage of polymer chains in this model. Surprisingly, the recently proposed four parameter extended Yao model shows even better capability to describe the measured extensional viscosity data than original six parameter Yao model due to its higher ability to predict planar extensional viscosity data as visible in Figure 9. This suggests that the extended Yao model is superior to the original Yao model. Interestingly, the modified Leonov model predictions, based on linear relaxation spectrum and nonlinear parameters $\xi, v$ identified on the strain-rate dependent uniaxial extensional viscosity only, are in very good agreement with the measured strain-rate dependent planar extensional viscosity, both measured at comparable strains (see Figure 10). This supports the physics behind the modified Leonov model as well as reliability and applicability of the performed measurements. It is important to mention that number of parameters utilized in the modified Leonov model is much higher in comparison to other tested models. It utilizes 12 modes discrete linear relaxation spectrum and additional 12 pairs of corresponding non-linear parameters $\xi, v$ identified from uniaxial extensional viscosity only (see Table 6). This makes the identification process 
for modified Leonov model much more complicated in comparison with low parametric models utilized in this work.

At the end of this chapter, main limitations of the Cogswell method, possible experimental difficulties and suggestions how to overcome them are provided and discussed.

- In the Cogswell method, inertia, shear normal stresses, WeissenbergRabinowitsch correction, slip, and fluid compressibility are neglected $[1,6$, 17]. Thus the experimental set-up for the given polymer melt should be optimized to fulfil as much as possible the applied assumptions, where it is possible. For example, running experiments at higher temperatures should be preferred to minimize effect of shear elasticity, slip and melt compressibility.

- $\quad$ Orifice dies having virtually zero length rather than extrapolation Bagley plot method should be preferred in order to minimize errors in the entrance pressure drop measurements due to slip, viscous heating and compressibility effects.

- Even if the Cogswell method was found to be fairly accurate at high rates $[11,13,45]$, it fails at low rates because the Trouton relationship is not handled correctly due to assumed kinematics $[10,55]$. This problem can be overcome by using a specific orifice die having L/D ratio equal to 0.1208 as shown in [10].

- Improper orifice die design leads to unwanted wetting and accumulation of the polymer melt at the die exit region, which generates significant error in the 
form of additional pressure drop [9, 11, 35, 56-58]. This problem can be avoided by using orifice dies with highly opened downstream region $[9,11$, 34-35] (see Figures 1-2).

- The flow is no homogeneous at the entry region of the die because mixed shear and extensional flow occur at the same time. In order to enhance the extensional flow components, abrupt $180^{\circ}$ entry angle dies can be used.

- Generated average values of extensional strain might be lower than those needed to reach steady state conditions. This can be overcome by increasing the barrel diameter and/or decreasing die diameter/gap size.

\section{CONCLUSION}

In this work, planar and uniaxial extensional viscosities for branched LDPE polymer melt has been determined through entrance pressure drop technique on conventional twin bore capillary rheometer by using novel circular and rectangle orifice dies and the obtained experimental data has been described by four different constitutive equations. It has been showed that chain branching causes the strain hardening occurrence in both, uniaxial and planar extensional viscosities and its maximum is shifted to the higher strain rates if the temperature is increased. The level of uniaxial extensional strain hardening for the branched LDPE sample has been found to be higher in comparison with the planar extensional viscosity within wide range of temperatures. It has been found that recently proposed non-Newtonian fluid model [36-37] and especially a few parametric extended Yao model [39] can represent steady shear, uniaxial and planar extensional viscosities for branched LDPE reasonably well. On the other hand, the modified White-Metzner model has failed in the prediction of 
the planar extensional viscosity. It has been revealed that the capability of the original Yao model to describe both measured extensional viscosities via few physics-based material parameters is good with small tendency to over predict strain hardening in the planar extensional viscosity. Moreover, it has been concluded that the extended Yao model is superior to original Yao model due to its higher overall capability to fit/predict measured extensional viscosity data by lower number of material parameters. Interestingly, the modified Leonov model predictions for the planar extensional viscosities have been revealed to be in very good agreement with the experimental data, which supports physics behind the model and reliability of the performed measurements.

It is believed that the proposed novel orifice die design for the planar extensional viscosity measurements can be considered as a very useful tool for better understanding of the polymer melt molecular structure, processing instabilities, optimization of polymer blends composition as well as for the constitutive equation testing purposes.

\section{ACKNOWLEDGMENTS}

The author wish to acknowledge Grant Agency of the Czech Republic (Grant No. 16-05886S) for the financial support. The author also wishes to acknowledge Martin Obadal (Borealis Polyolefine) for donation LDPE CA820, which have been used in this work. 


\section{REFERENCES}

1. F. A. Morrison, Understanding Rheology, New York: Oxford University Press, 2001.

2. C. W. Macosko, Rheology: Principles, Measurements, and Applications, New York: Wiley-VCH, 1994.

3. Muenstedt, H.: New Universal Extensional Rheometer for Polymer Melts. Measurements on a Polystyrene Sample. (1979) Journal of Rheology, 23(4), 421436.

4. Sentmanat, M.L.: Miniature universal testing platform: From extensional melt rheology to solid-state deformation behaviour (2004) Rheologica Acta, 43(6), 657-669.

5. Sentmanat, M., Wang, B.N., McKinley, G.H.: Measuring the transient extensional rheology of polyethylene melts using the SER universal testing platform, Journal of Rheology, 49(3), 585-606 (2005).

6. F. N. Cogswell: Converging flow of polymer melts in extrusion dies, Polym. Eng. Sci. 12, 64-73 (1972).

7. D. M. Binding: An approximate analysis for contraction and converging flows, $J$. Non-Newtonian Fluid Mech. 27, 173-189 (1988).

8. A. G. Gibson: Die entry flow of reinforced polymers, Composites 20, 57-64 (1989).

9. S. Kim and J. M. Dealy: Design of an orifice die to measure entrance pressure drop, J. Rheol. 45, 1413-1419 (2001). 
10. M. Zatloukal, J. Vlcek, C. Tzoganakis and P. Saha, J.: Improvement in techniques for the determination of extensional rheological data from entrance flows: Computational and experimental analysis, Non-Newtonian Fluid Mech. 107, 1337 (2002).

11. M. Zatloukal and J. Musil: Analysis of entrance pressure drop techniques for extensional viscosity determination, Polym. Test. 28, 843-853 (2009).

12. K. Walczak, M. Gupta, K. A. Koppi, J. Dooley and M. A. Spalding: Elongational viscosity of LDPEs and polystyrenes using entrance loss data, Polym. Eng. Sci. 48, 223-232 (2008).

13. H. M. Laun and H. Schuch: Transient elongational viscosities and drawability of polymer melts, J. Rheol. 33, 119-175 (1989).

14. M. Kraft, "Untersuchungen zur scherinduzierten rheologischen Anisotropie von verschiedenen Polyethylen- Schmelzen”, Ph.D. Thesis, Dissertation ETH Zurich Nr. 11417, 1996.

15. P. Hachmann, "Multiaxiale Dehnung von Polymerschmelzen", Ph.D. Thesis, Dissertation ETH Zurich Nr. 11890, 1996.

16. J. Meissner, S. E. Stephenson, A. Demarmels and P. Portman: Multiaxial elongational flows of polymer melts-classification and experimental realization, $J$. Non-Newtonian Fluid Mech. 11, 221-237 (1982).

17. F.N. Cogswell: Measuring the Extensional Rheology of Polymer Melts, Trans. Soc. Rheol., 16(3), 383-403 (1972). 
18. H. Münstedt: Dependence of the Elongational Behavior of Polystyrene Melts on Molecular Weight and Molecular Weight Distribution, Journal of Rheology, 24(6), 847-867 (1980).

19. H. Münstedt, H.M. Laun: Elongational properties and molecular structure of polyethylene melts, Rheologica Acta, 20(3), 211-221 (1981).

20. H. Münstedt, S. Kurzbeck, L. Egersdörfer: Influence of molecular structure on rheological properties of polyethylenes Part II. Elongational behavior, Rheologica Acta, 37(1), 21-29 (1998).

21. P. Spitael, C.W. Macosko: Strain hardening in polypropylenes and its role in extrusion foaming, Polymer Engineering and Science, 44(11), 2090-2100 (2004).

22. D. Auhl, J. Stange, H. Münstedt, B. Krause, D. Voigt, A. Lederer, U. Lappan, K. Lunkwitz: Long-chain branched polypropylenes by electron beam irradiation and their rheological properties, Macromolecules, 37(25), 9465-9472 (2004).

23. J. M. Dealy and R. G. Larson, Structure and rheology of molten polymers: from structure to flow behavior and back again (Hanser Publishers, München, 2006).

24. V. Hugo Rolón-Garrido, M. Zatloukal, M.H. Wagner: Increase of long-chain branching by thermo-oxidative treatment of LDPE: Chromatographic, spectroscopic, and rheological evidence, Journal of Rheology, 57(1), 105-129 (2013).

25. J. M. Dealy and J. Wang, Melt rheology and its applications in the plastics industry 2nd ed. (Springer, Dordrecht, 2013).

26. H. Münstedt and F. R. Schwarzl, Deformation and flow of polymeric materials (Springer, Heidelberg, 2014). 
27. A.T. Hedegaard, L. Gu, C.W. Macosko: Effect of extensional viscosity on cocontinuity of immiscible polymer blends, Journal of Rheology, 59(6), 13971417 (2015).

28. R. J. Andrade and J. M. Maia: A study on the flow, failure, and rupture mechanisms of low-density polyethylene in controlled-stress uniaxial extensional flow, J. Rheol. 55, 925-937 (2011).

29. T. I. Burghelea, Z. Stary and H. Münstedt: On the " viscosity overshoot" during the uniaxial extension of a low density polyethylene, J. Non-Newtonian Fluid Mech. 166, 1198-1209 (2011).

30. H. K. Rasmussen and O. Hassager: Reply to: 'On the "viscosity overshoot" during the uniaxial extension of a low density polyethylene', J. Non-Newtonian Fluid Mech. 171-172, 106 (2012).

31. T. I. Burghelea, Z. Stary and H. Münstedt: Response to the "Reply to: 'On the "viscosity overshoot" during the uniaxial extension of a low density polyethylene' by Rasmussen et al.", J. Non-Newtonian Fluid Mech. 171-172, 107-108 (2012).

32. H. Münstedt, Z. Starý: Steady states in extensional flow of strain hardening polymer melts and the uncertainties of their determination, Journal of Rheology, 57(4), 1065-1077 (2013).

33. D. Auhl, D. M. Hoyle, D. Hassell, T. D. Lord, O. G. Harlen, M. R. Mackley and T. C. B. McLeish: Cross-slot extensional rheometry and the steady-state extensional response of long chain branched polymer melts, J. Rheol. 55, 875-900 (2011). 
34. M. Zatloukal, J. Musil: Extrusion head with inert capillary of zero length, Patent CZ 304382 B6, 2014.

35. M. Zatloukal: Extrusion head with inert flat slit of zero length, Patent CZ 305409 B6, 2015.

36. M. Zatloukal: A simple phenomenological non-Newtonian fluid model, J. NonNewtonian Fluid Mech. 165, 592-595 (2010).

37. M. Zatloukal: Novel non-Newtonian fluid model for polymer melts, Annual Technical Conference - ANTEC, Conference Proceedings 1, 92-96 (2011).

38. D. Yao: A non-Newtonian fluid model with an objective vorticity, Journal of Non-Newtonian Fluid Mechanics, 218, 99-105 (2015).

39. D. Yao, A non-Newtonian fluid model with finite stretch and rotational recovery, Journal of Non-Newtonian Fluid Mechanics, 230, 12-18 (2016).

40. H. A. Barnes, G. P. Roberts: A simple empirical model describing the steady-state shear and extensional viscosities of polymer melts, J. Non-Newtonian Fluid Mech. 44, 113-126 (1992).

41. A. I. Leonov: Nonequilibrium thermodynamics and rheology of viscoelastic polymer media, Rheol. Acta, 15, 85-98 (1976).

42. M. Zatloukal: Differential viscoelastic constitutive equations for polymer melts in steady shear and elongational flows, J. Non-Newtonian Fluid Mech. 113, 209-227 (2003).

43. M. Padmanabhan, C.W. Macosko: Extensional viscosity from entrance pressure drop measurements. Rheol. Acta, 36, 144-151 (1997). 
44. A.D. Gotsis, A. Odriozola: The relevance of entry flow measurements for the estimation of extensional viscosity of polymer melts, Rheol. Acta, 37, 430-437 (1998).

45. Aho, J., Rolón-Garrido, V.H., Syrjälä, S., Wagner, M.H.: Extensional viscosity in uniaxial extension and contraction flow-Comparison of experimental methods and application of the molecular stress function model, Journal of Non-Newtonian Fluid Mechanics, 165(5-6), 212-218 (2010).

46. M. Simhambhatla and A. I. Leonov: On the rheological modeling of viscoelastic polymer liquids with stable constitutive equations, Rheol. Acta 34, 259-273 (1995).

47. A. I. Leonov, "Constitutive Equations for Viscoelastic Fluids: Formulation, Analysis and Comparison with Data" in Advances In the Flow and Rheology of Non-Newtonian Fluids, Part A, edited by D. A. Siginer, D. De Kee and R. P. Chhabra, New York: Elsevier, 1999.

48. R.G. Larson, Constitutive equations for polymer melts and solution, Boston: Butterworth Publishers, 1988.

49. T. Dobroth, L. Erwin: Causes of Edge Beads in Cast Films, Polymer Engineering and Science, 26(7), 462-467 (1986).

50. N. Satoh, H. Tomiyama, T. Kajiwara: Viscoelastic simulation of film casting process for a polymer melt, Polymer Engineering and Science, 41(9), 1564-1579 (2001). 
51. T. Kajiwara, M. Yamamura, T. Asahina: Relationship between neck-in phenomena and rheological properties in film casting, Nihon Reoroji Gakkaishi, 34(2), 97-103 (2006).

52. S. Shiromoto, Y. Masutani, M. Tsutsubuchi, Y. Togawa, T. Kajiwara, A neck-in model in extrusion lamination process, Polymer Engineering and Science, 50(1), 22-31 (2010).

53. S. Shiromoto, Y. Masutani, M. Tsutsubuchi, Y. Togawa, T. Kajiwara, The effect of viscoelasticity on the extrusion drawing in film-casting process, Rheologica Acta, 49(7), 757-767 (2010).

54. S. Shiromoto, The mechanism of neck-in phenomenon in film casting process, International Polymer Processing, 29(2), 197-206 (2014).

55. M.E. Mackay, G. Astarita, Analysis of entry flow to determine elongation flow properties revised, Journal of Non-Newtonian Fluid Mechanics, 70, 219-235 (1997).

56. J. Sunder, A. Goettfert, Extensional flow properties from entrance pressure measurements using zero length die versus Bagley correction, SPE ANTEC, 1036$1042(2001)$.

57. J. Aho, S. Syrjälä, Determination of the entrance pressure drop in capillary rheometry using Bagley correction and zero-length capillary, Annual Transaction of the Nordic Rheology Society, 14, (2006).

58. J. Aho, S. Syrjälä, Evaluation of different methods for determining the entrance pressure drop in capillary rheometry, Applied Rheology, 18(6), 63258-1-63258-5 (2008). 
Table 1. Cogswell model summarization for uniaxial/planar extensional viscosity determination $[6,12]$.

\begin{tabular}{|c|c|c|}
\hline & Uniaxial extensional flow & Planar extensional flow \\
\hline Apparent shear rate & $\dot{\gamma}_{\mathrm{app}, \mathrm{U}}=\frac{4 Q}{\pi R^{3}}$ & $\dot{\gamma}_{\mathrm{app}, \mathrm{P}}=\frac{6 Q}{w h^{2}}$ \\
\hline Corrected shear stress & $\tau_{\mathrm{xy}, \mathrm{corr}, \mathrm{U}}=\frac{\left(P_{\mathrm{L}, \mathrm{U}}-P_{0, \mathrm{U}}\right) R}{2 L_{\mathrm{U}}}$ & $\tau_{\mathrm{xy}, \mathrm{corr}, \mathrm{P}}=\frac{\left(P_{\mathrm{L}, \mathrm{P}}-P_{0, \mathrm{P}}\right) h}{2 L_{\mathrm{P}}}$ \\
\hline $\begin{array}{l}\text { Apparent index of non- } \\
\text { Newtonian behaviour }\end{array}$ & $n_{\mathrm{U}}=\frac{d \log \left(\tau_{\mathrm{xy}, \mathrm{corr}, \mathrm{U}}\right)}{d \log \left(\dot{\gamma}_{\mathrm{app}, \mathrm{U}}\right)}$ & $n_{\mathrm{P}}=\frac{d \log \left(\tau_{\mathrm{xy}, \mathrm{corr}, \mathrm{P}}\right)}{d \log \left(\dot{\gamma}_{\mathrm{app}, \mathrm{P}}\right)}$ \\
\hline Extensional stress & $\sigma_{\mathrm{E}, \mathrm{U}}=\frac{3}{8}\left(n_{\mathrm{U}}+1\right) P_{0, \mathrm{U}}$ & $\sigma_{\mathrm{E}, \mathrm{P}}=\frac{1}{2}\left(n_{\mathrm{P}}+1\right) P_{0, \mathrm{P}}$ \\
\hline Extensional strain rate & $\dot{\varepsilon}_{\mathrm{U}}=\frac{4 \tau_{\mathrm{xy}, \mathrm{corr}, \mathrm{U}} \dot{\gamma}_{\mathrm{app}, \mathrm{U}}}{3(n+1) P_{0, \mathrm{U}}}$ & $\dot{\varepsilon}_{\mathrm{U}}=\frac{2 \tau_{\mathrm{xy}, \mathrm{corr}, \mathrm{P}} \dot{\gamma}_{\mathrm{app}, \mathrm{P}}}{3(n+1) P_{0, \mathrm{P}}}$ \\
\hline Extensional viscosity & $\eta_{\mathrm{E}, \mathrm{U}}=\frac{\sigma_{\mathrm{E}, \mathrm{U}}}{\dot{\varepsilon}_{\mathrm{U}}}$ & $\eta_{\mathrm{E}, \mathrm{P}}=\frac{\sigma_{\mathrm{E}, \mathrm{P}}}{\dot{\varepsilon}_{\mathrm{P}}}$ \\
\hline
\end{tabular}

TABLE 2. Generalized Newtonian model parameters for $T=170^{\circ} \mathrm{C}$

\begin{tabular}{ccccccccc}
\hline $\begin{array}{c}\boldsymbol{\eta}_{\mathbf{0}} \\
(\mathbf{P a} \cdot \mathbf{s})\end{array}$ & $\begin{array}{c}\lambda \\
(\mathbf{s})\end{array}$ & $\begin{array}{c}\boldsymbol{a} \\
(-)\end{array}$ & $\begin{array}{c}\boldsymbol{n} \\
(-)\end{array}$ & $\begin{array}{c}\boldsymbol{A} \\
(\mathbf{s})\end{array}$ & $\begin{array}{c}\boldsymbol{\beta} \\
(-)\end{array}$ & $\begin{array}{c}\boldsymbol{\zeta} \\
(-)\end{array}$ & $\begin{array}{c}A_{1} \\
(\mathbf{P a})\end{array}$ & $\begin{array}{c}\psi \\
(-)\end{array}$ \\
\hline 4376.6 & 0.2151 & 0.4919 & 0.3464 & 0.051671 & 0.0675 & 0.056076 & $2.4 .10^{-5}$ & 8 \\
\hline
\end{tabular}

TABLE 3. Original Yao model parameters for $T=170^{\circ} \mathrm{C}$

\begin{tabular}{cccccc}
\hline $\boldsymbol{\eta}_{\mathbf{0}}$ & $\lambda$ & $\boldsymbol{S}_{\boldsymbol{0}}$ & $\boldsymbol{\mu}_{\mathrm{S}} / \boldsymbol{\eta}_{\mathbf{0}}$ & $\boldsymbol{K}_{\boldsymbol{I}}$ & $\boldsymbol{k}$ \\
$(\mathbf{P a . s})$ & $(\mathbf{s})$ & $(-)$ & $(-)$ & $(\mathbf{s})$ & $(-)$ \\
\hline 4376.6 & 0.08 & 1.54975 & 10.94593 & 3.15680 & 0.48774 \\
\hline
\end{tabular}

TABLE 4. Extended Yao model parameters for $T=170^{\circ} \mathrm{C}$

\begin{tabular}{cccc}
\hline $\begin{array}{c}\boldsymbol{\eta}_{\mathbf{0}} \\
(\text { Pa.s })\end{array}$ & $\begin{array}{c}\lambda \\
(\mathbf{s})\end{array}$ & $\begin{array}{c}\boldsymbol{S}_{\boldsymbol{0}} \\
(-)\end{array}$ & $\begin{array}{c}\boldsymbol{\beta} \boldsymbol{\theta} \\
(-)\end{array}$ \\
\hline 4376.6 & 0.3965 & 2.50607 & 0.08487 \\
\hline
\end{tabular}

TABLE 5. Modified White-Metzner model parameters for $T=170^{\circ} \mathrm{C}$

\begin{tabular}{cccccc}
\hline $\begin{array}{c}\eta_{\mathbf{0}} \\
(\mathbf{P a} \mathbf{s})\end{array}$ & $\begin{array}{c}\lambda \\
(\mathbf{s})\end{array}$ & $\begin{array}{c}\boldsymbol{a} \\
(-)\end{array}$ & $\begin{array}{c}\boldsymbol{n} \\
(-)\end{array}$ & $\begin{array}{c}\boldsymbol{\lambda}_{\mathbf{0}} \\
(\mathbf{s})\end{array}$ & $\begin{array}{c}\boldsymbol{K}_{\mathbf{2}} \\
(\mathbf{s})\end{array}$ \\
\hline 4376.6 & 0.2151 & 0.4919 & 0.3464 & 0.936 & 1.1286 \\
\hline
\end{tabular}


TABLE 6. Modified Leonov model parameters for $T=170^{\circ} \mathrm{C}$

\begin{tabular}{ccccc}
\hline & \multicolumn{2}{c}{ Maxwell parameters } & \multicolumn{2}{c}{ mLeonov model } \\
$\mathbf{i}$ & $\boldsymbol{\lambda}_{\mathbf{i}}(\mathbf{s})$ & $\boldsymbol{G}_{\mathbf{i}}(\mathbf{P a})$ & $\boldsymbol{\xi}$ & $\boldsymbol{v}$ \\
\hline 1 & 0.00070958 & 83406.20000 & 0 & 1.000 \\
2 & 0.00221000 & 40900.00000 & 0 & 1.000 \\
3 & 0.00687000 & 14940.90000 & 2.000 & 0.025 \\
4 & 0.02137000 & 12444.40000 & 1.180 & 0.020 \\
5 & 0.06647000 & 5911.720000 & 0.750 & 0.020 \\
6 & 0.20680000 & 2964.370000 & 0.500 & 0.020 \\
7 & 0.64336000 & 1233.070000 & 0.100 & 0.020 \\
8 & 2.00152000 & 458.1260000 & 0.090 & 0.080 \\
9 & 6.22686000 & 95.86140000 & 0 & 1.000 \\
10 & 19.3721000 & 14.70970000 & 0 & 1.000 \\
11 & 60.2679000 & 4.097244707 & 0 & 1.000 \\
12 & 187.497000 & 0.071474080 & 0 & 1.000 \\
\hline
\end{tabular}



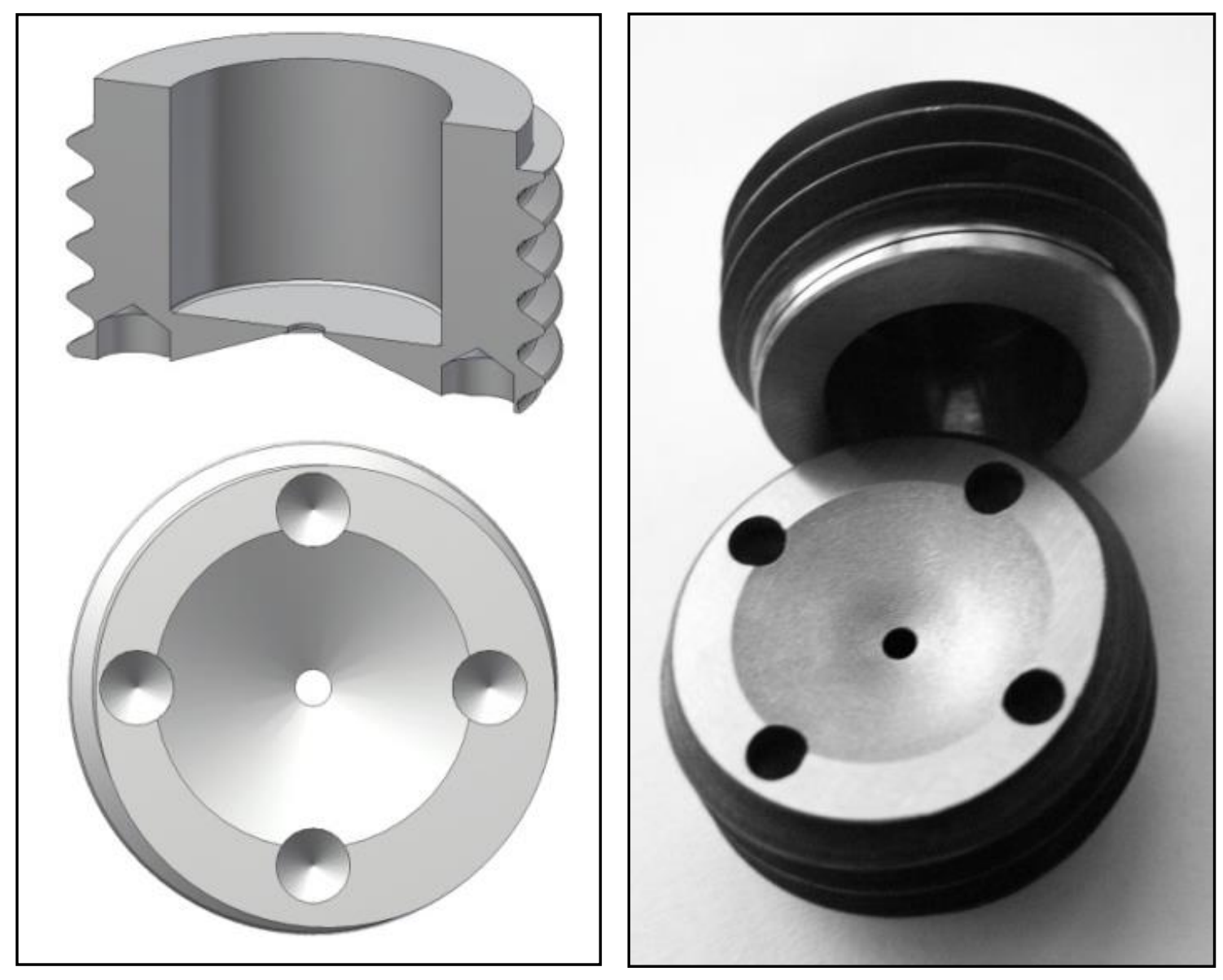

FIGURE 1. Patented circular orifice die with abrupt entry utilized for uniaxial extensional viscosity measurements developed in [11,34]. 
2a)

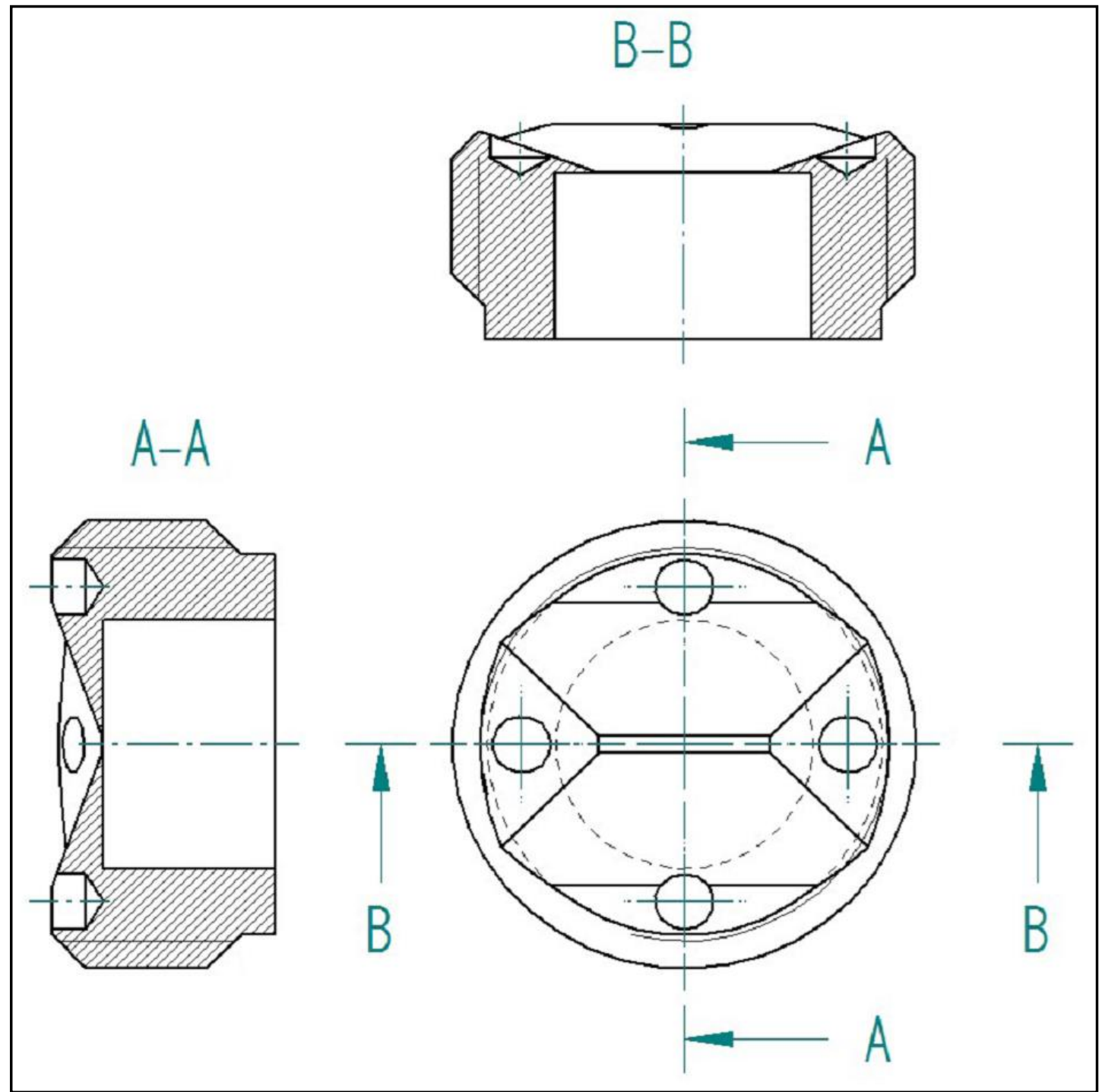

2b)

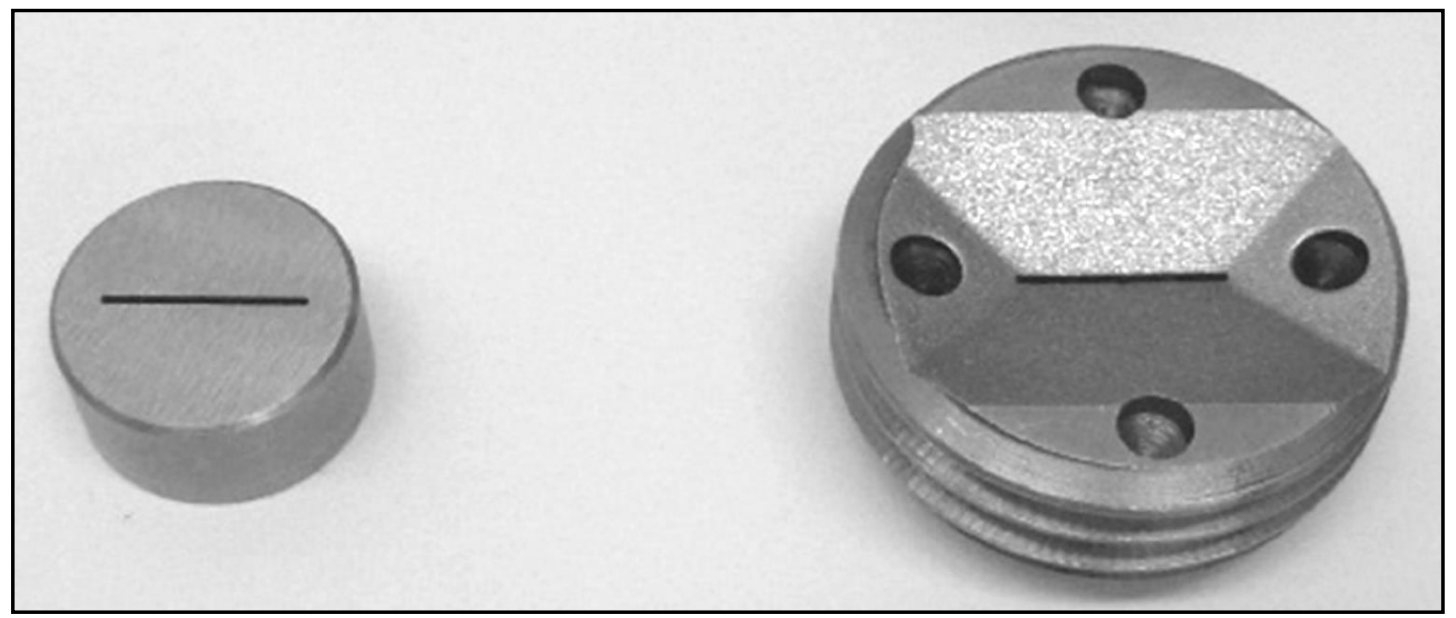

FIGURE 2. Patented rectangle dies for planar extensional viscosity measurements [35]. 2a) Sketch of the rectangle orifice die with abrupt entry. 2b) Set of rectangle dies for the planar extensional viscosity measurements on twin bore capilary rheometer (left - long die, right - novel orifice die). 


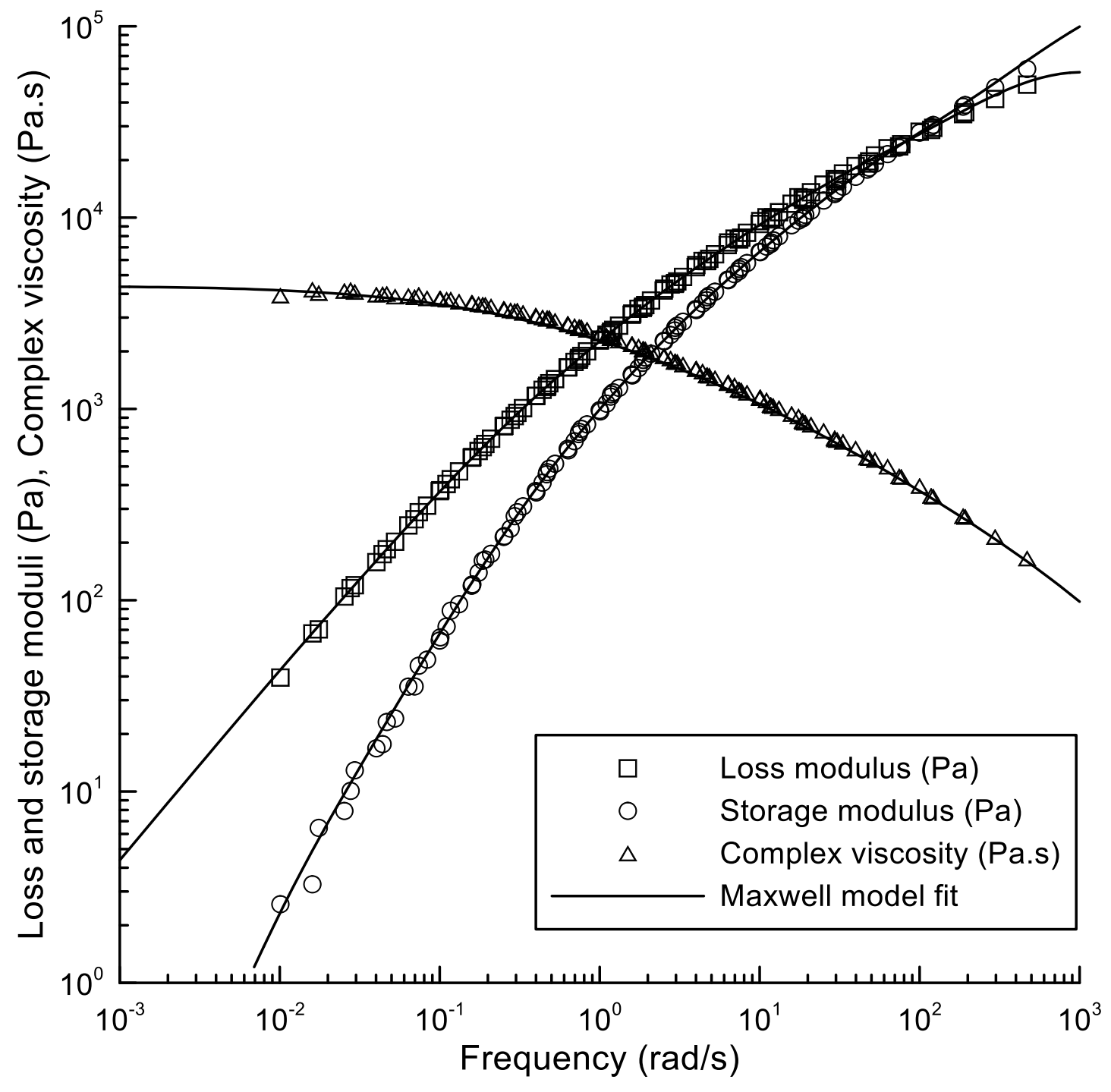

FIGURE 3. Comparison of Maxwell model with measured complex viscosity, storage and loss moduli for LDPE polymer in oscillatory shear flow at the reference temperature $170^{\circ} \mathrm{C}$. 


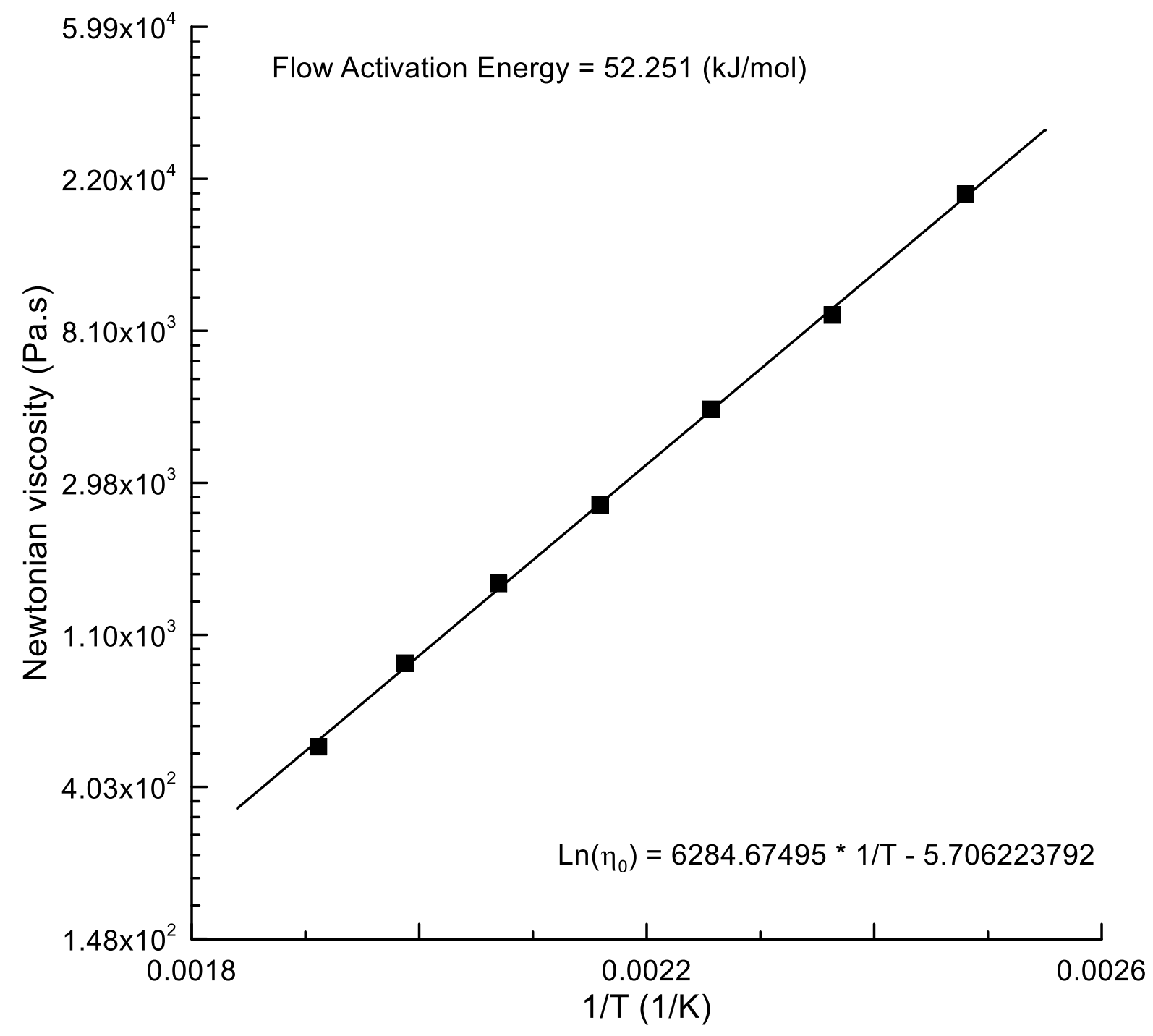

FIGURE 4. Arrhenius plot for LDPE sample. 


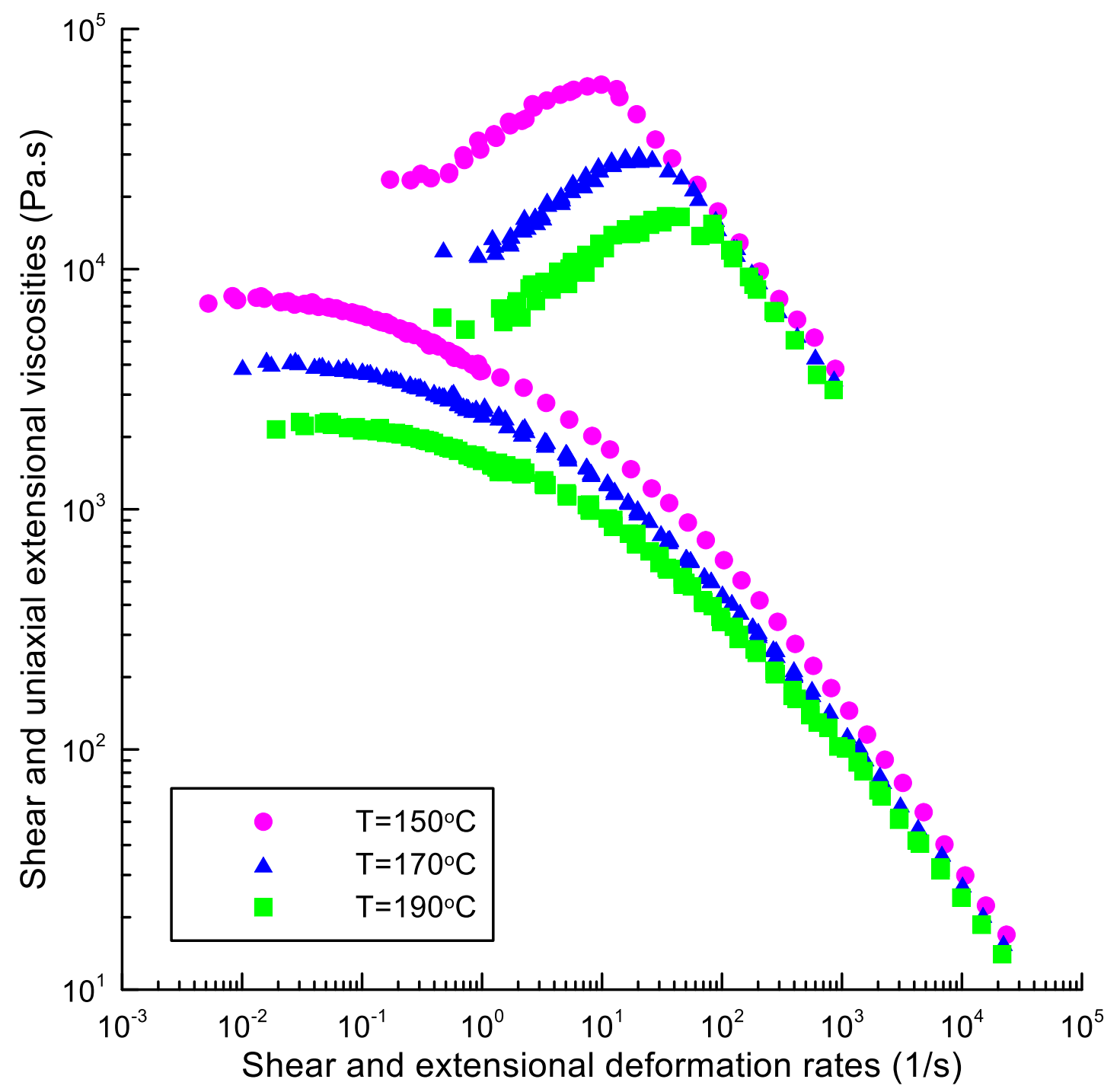

FIGURE 5. Experimentally determined steady shear and uniaxial extensional viscosities for LDPE sample at three different temperatures (top - uniaxial extensional viscosity, bottom - shear viscosity). 


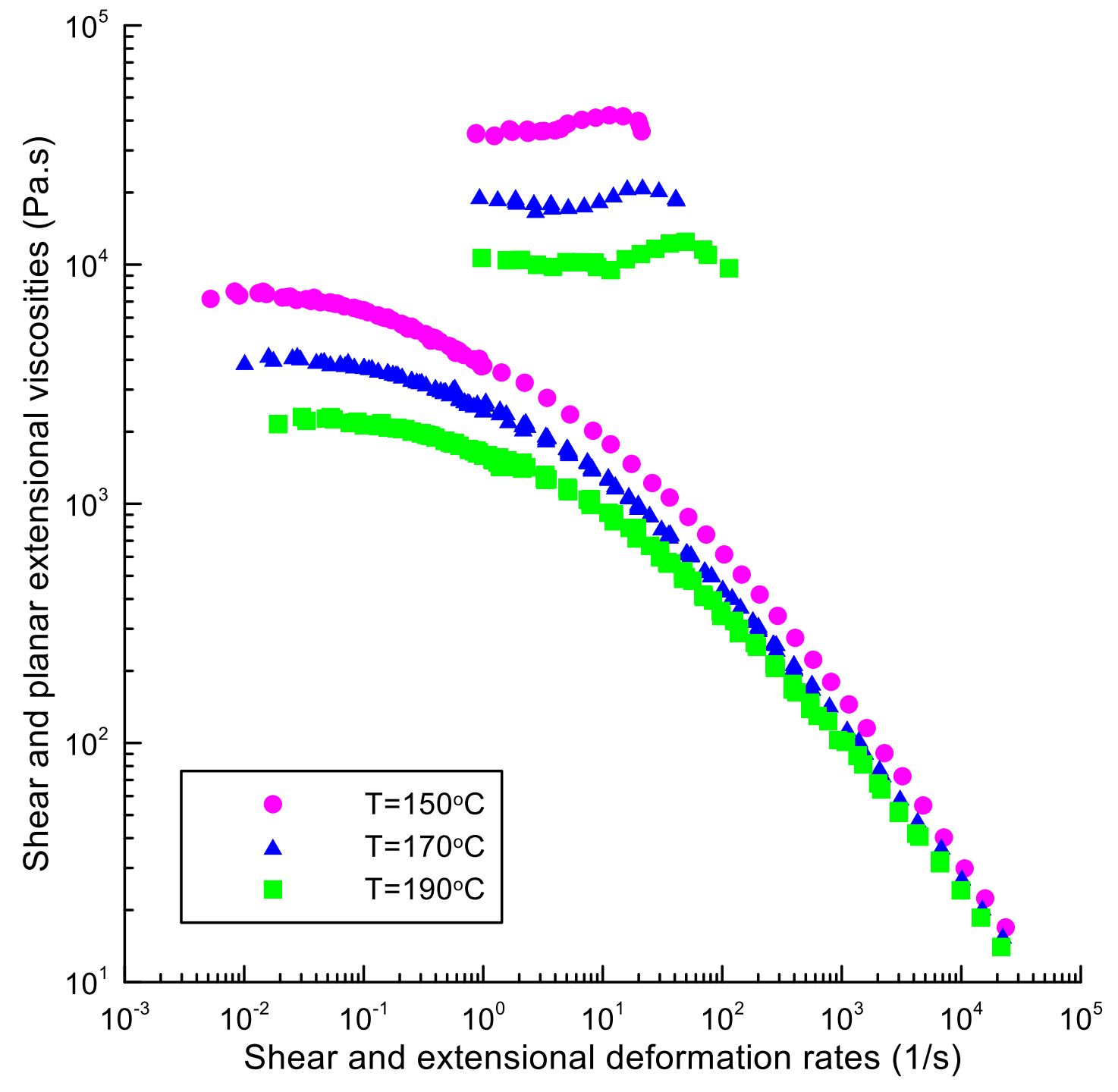

FIGURE 6. Experimentally determined steady shear and planar extensional viscosities for LDPE sample at three different temperatures (top - planar extensional viscosity, bottom - shear viscosity). 


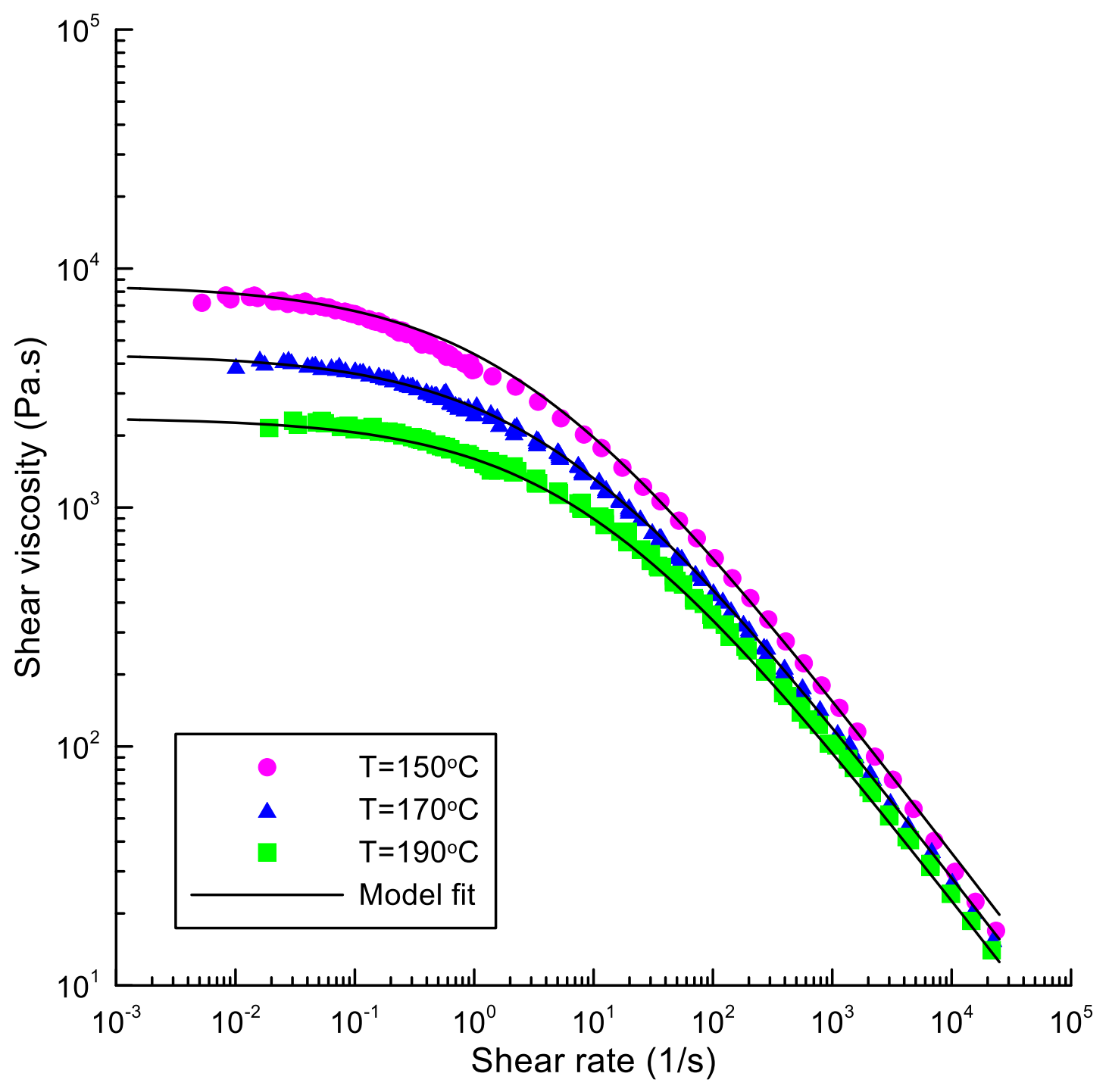

FIGURE 7. Comparison between the utilized generalized Newtonian/modified White-Metzner model fits (solid lines) and measured steady shear viscosities (symbols) for LDPE sample. 

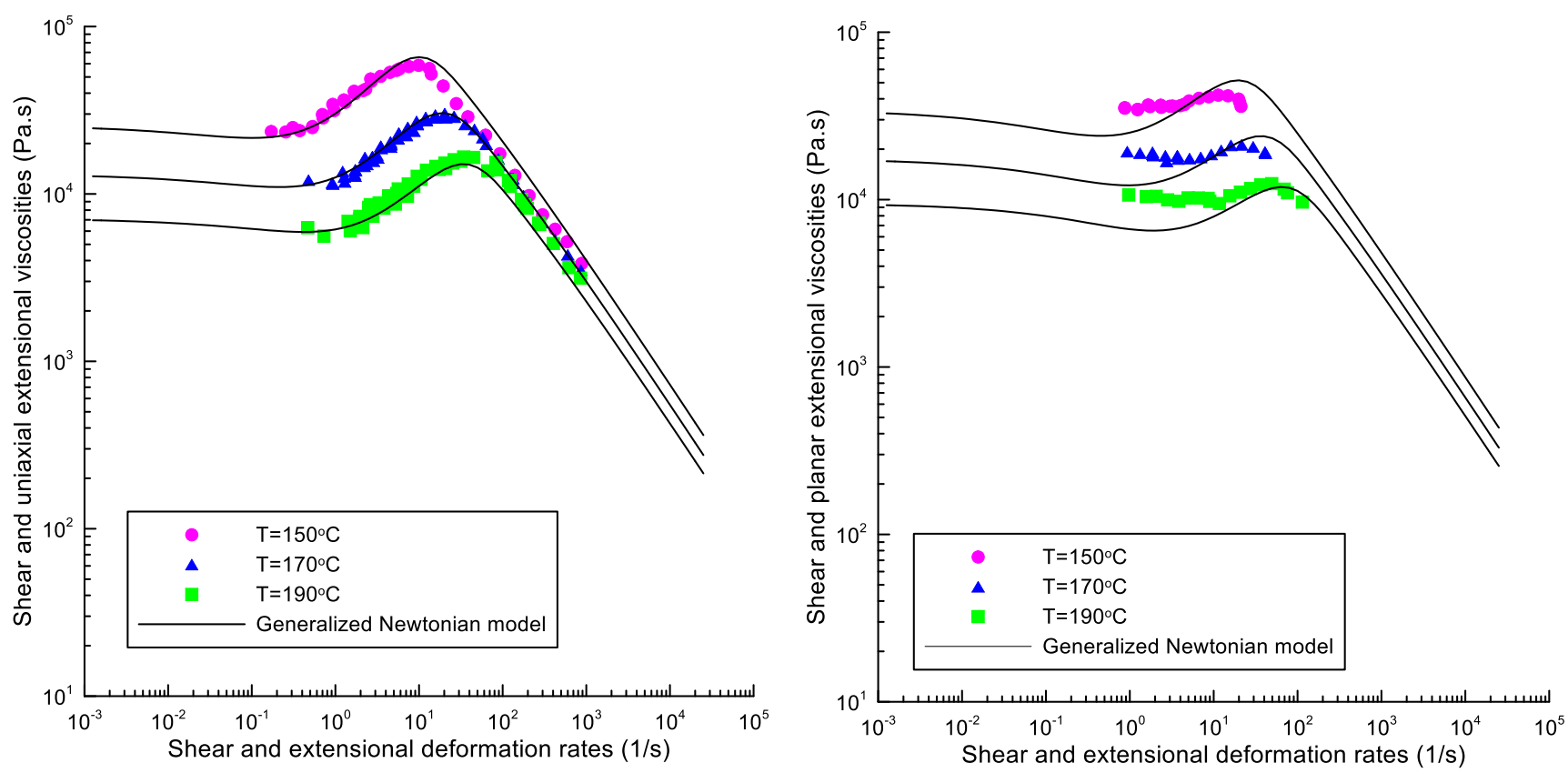

FIGURE 8. Comparison between the utilized Generalized Newtonian model fits/predictions (solid lines) and measured uniaxial and planar extensional viscosities (symbols) for LDPE sample at three different temperatures. 

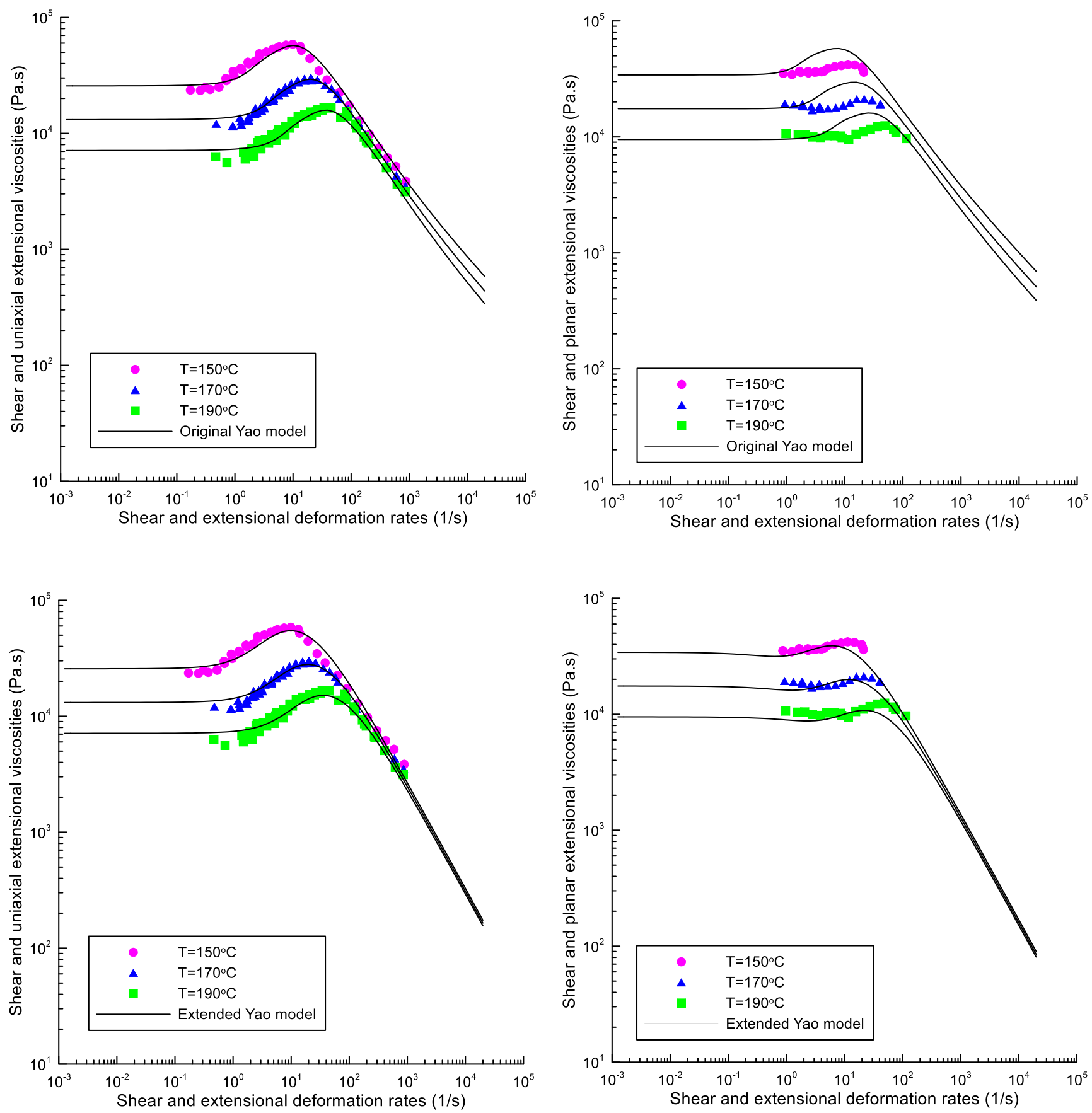

FIGURE 9. Comparison between the utilized model fits/predictions (solid lines) and measured uniaxial and planar extensional viscosities (symbols) for LDPE sample at three different temperatures (top Original Yao model, bottom - Extended Yao model). 

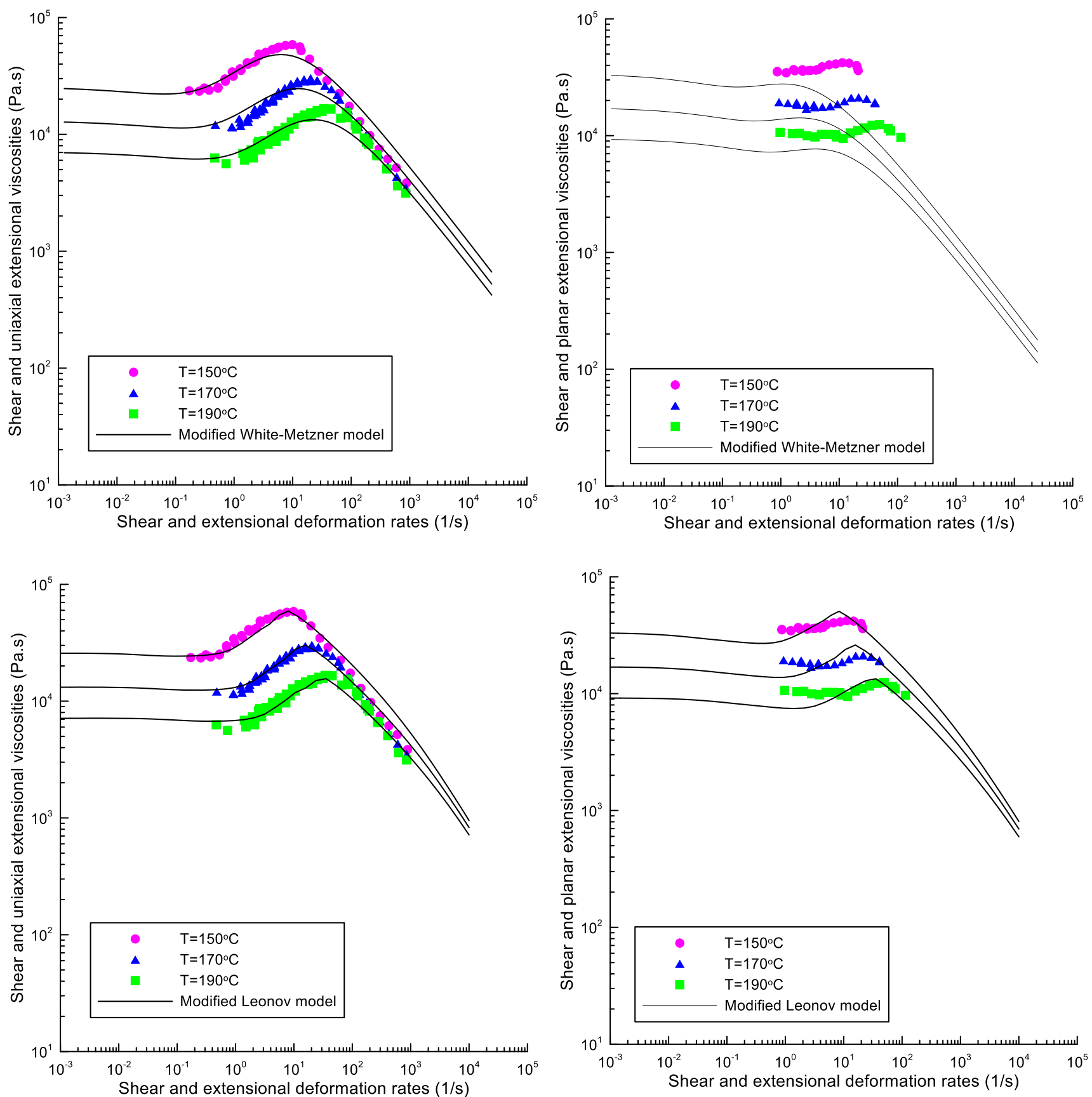

FIGURE 10. Comparison between the utilized model fits/predictions (solid lines) and measured uniaxial and planar extensional viscosities (symbols) for LDPE sample at three different temperatures (top - Modified White-Metzner model, bottom - Modified Leonov model model). 